\title{
RADIOLOGICAL RISK ASSESSMENT DUE TO INGESTION OF SOME BOTTLED DRINKING WATER ON THE GHANAIAN MARKET
}

\author{
M.O. Portuphy*, A. FaAnu And A. SAwyerr \\ (M.O.P.: School of Nuclear and Allied Sciences, University of Ghana; A. F.: Ghana Nuclear \\ Regulatory Authority; A. S.: CSIR-Institute for Scientific and \\ Technological Information (INSTI), Ghana). \\ *Corresponding author's email: moportuphy@st.ug.edu.gh
}

\begin{abstract}
Activity concentrations of the Naturally Occurring Radioactive Materials (NORMs) in some bottled drinking water brands obtained from some supermarkets in Accra were analyzed using gamma spectrometry. $40 \mathrm{~K}$ activity concentrations were in the range of $3.57-5.47 \mathrm{~Bq} / \mathrm{L}$, the highest occurring in brand L9. Similarly, ${ }^{232} \mathrm{Th}$ activity concentrations were in the range of $0.30-0.56 \mathrm{~Bq} / \mathrm{L}$ with the highest occurring in brand L8 ${ }^{226} \mathrm{Ra}$ was identified in eleven brands with the remaining 5 below detection limit. The highest value $(0.53 \mathrm{~Bq} / \mathrm{L})$ occurred in brand L9. Comparison of the mean concentrations showed significant differences at $(\alpha=0.05)$ between the various brands of bottled water. Estimated committed effective doses were generally below $0.1 \mathrm{mSv} / \mathrm{a}$ for all age groups with the exception of children $<1 \mathrm{yr}$. Estimated lifetime cancer and hereditary risk were done using the ICRP risk assessment methodology.
\end{abstract}

\section{Introduction}

Natural radiation comes from cosmic rays, naturally-occurring radioactive elements in the earth's crust, and radioactive decay products. Since these radionuclides are present in soil and rock, they can also be found in groundwater and surface water. Natural radionuclides commonly found in waters include ${ }^{238} \mathrm{U},{ }^{234} \mathrm{U}$, ${ }^{232} \mathrm{Th},{ }^{226} \mathrm{Ra},{ }^{238} \mathrm{Ra},{ }^{222} \mathrm{Rn},{ }^{210} \mathrm{~Pb}$ and $40 \mathrm{~K}$ (Dragani et al., 1990). The existence of these radionuclides normally occurs in wells dug deep into aquifers containing radionuclides of variable oxidation states. The mineralized radionuclides dissolve slowly; however, for water that has high contact time with these rocks, there is a higher probability of significant radionuclide concentration (Choppin et al, 2002).
The concentration is however, not necessarily restricted to the surface geological characteristics. It is also dependent on the physical and chemical factors (e.g. T, $\mathrm{P}, \mathrm{O}_{2}$, etc.) prevailing in the aquifers for which reason radionuclide concentrations may vary for aquifers that are few meters apart. Even variable ground flow patterns may result in seasonal variations in radionuclide concentrations (Lieser et al., 1990).

Water is a basic necessity for biological survival and continuity, hence the need for it to be accessible, adequate and safe. In sub-Saharan Africa, the population relying on improved water sources has increased from $49 \%$ to $63 \%$ from 1990 to 2011 respectively (UN, 2013). 
Ghana has climbed the pedestal into becoming a middle-income country with a high consumist middle income class. Over the years, a number of bottled water companies have emerged to meet the demands of the middle class due to its perceived quality and safety. However, most of the bottled water companies (BWC's) limit their water quality assessment to microbial, chemical and acceptability requirements with no further studies to quantify the radionuclide contents (Dueňas et al., 1997). Water from aquifers and surface water areas are ideal sources for the BWC's due to their rich mineral contents. However, the possible presence of significant amounts of radionuclides as explained earlier, the uncontrolled anthropogenic exploits that occur at aquifer locations and the weakness of the regulatory agencies to enforce standards gives enough reason to assess the radiological components of some bottled drinking water on the Ghanaian market.

Radiological aspect of drinking water Naturally occurring radionuclides in drinking water usually give radiation doses higher than those provided by artificially produced radionuclides and are therefore of greater concern (Dozol, 1993). This resulted in screening and guidance levels set by the WHO.

In the third edition of the International Commission on Radiological Protection (ICRP) recommendations (ICRP, 2007), the individual dose criterion (IDC) was based on screening levels of $0.5 \mathrm{~Bq} / 1$ for gross alpha activity and $1 \mathrm{~Bq} / 1$ for gross beta activity (WHO, 2011). The IDC was set at $0.1 \mathrm{mSv} /$ year representing below $5 \%$ of the average annual dose due to natural radiation. The guidance levels are not mandatory compliance limits; however, they serve the purpose of prompting further investigations and specific radionuclide analysis.

\section{Sampling}

\section{Experimental}

Most bottled drinking water are sourced from aquifers with a few sourced from surface waters. Study was done on their availability across the country and 16 brands were selected. 10 are Natural Mineral Waters (NMW), five are Prepared Water (PW) and one uses sources for which NMW or PW are classified. The NMW's are normally bottled at source with the whole factory set-up located near the source. However, the PW's are drawn from municipal tap water systems which are drawn from surface waters and consequently into large reservoirs located at manufacturers premises. Two dominant aquifer sources were highly exploited; the Medie aquifer enclaves and the relatively isolated mountains on the Dodowa-Agormanya low lying plains which form part of the pre-Cambrian crystalline basement complex rocks. Fig. 1 is a map showing the source of water to the bottling water companies.

Grab samples were obtained directly from the shelves of supermarkets and information as provided by the label was recorded. Accompanying labels were subsequently removed and replaced with different identities from L1 to L16 (see Table A1).

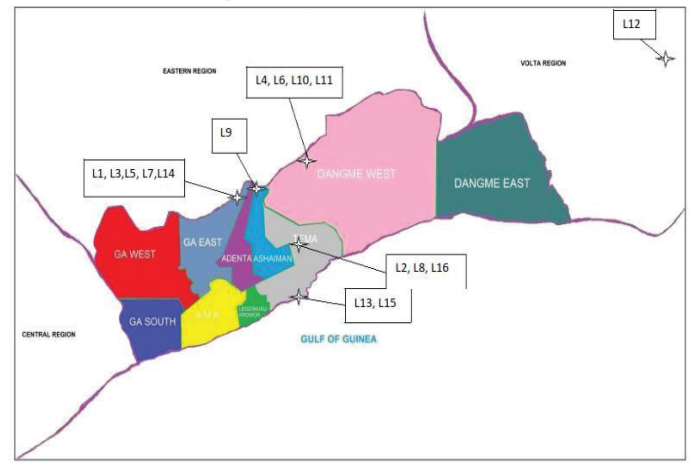

Fig. 1: Production site of different brands of BW samples used for analysis. 


\section{Norm determination}

Sample preparation and measurement by Gamma Spectroscopy

The water samples were transferred into 1L Marinelli beakers which were made of chemical resistant polypropylene. Marinelli beakers are used for gamma spectroscopy measurements due to their light weight and their ability to eliminate leaks. Prior to filling the beaker, acetone-soaked cotton was used to wipe the inside and allowed to volatize. The beaker was subsequently sealed hermetically with paper tape and adequately labelled.

\section{Energy calibration of gamma spectrometer}

Energy calibration was accomplished by measuring the spectrum of a source emitting gamma-rays of precisely known energy and comparing the measured peak position with energy (Gilmore, 2008). This was done using a mixed radionuclide source containing ${ }^{241} \mathrm{Am},{ }^{109} \mathrm{Cd}$, ${ }^{113} \mathrm{Sn},{ }^{85} \mathrm{Sr},{ }^{57} \mathrm{Co},{ }^{139} \mathrm{Ce},{ }^{137} \mathrm{Cs}$, and ${ }^{88} \mathrm{Y}$. These radionuclides provide a range of energies between $60 \mathrm{keV}$ and $2000 \mathrm{keV}$. The mixed radionuclide standard was counted long enough (36000s) on the detector (HPGe) to produce well defined photopeaks.

\section{Efficiency calibration}

For efficiency calibration, nuclides with known accurate gamma ray emission probabilities and known source activities were used. Certified multi radionuclide standard from the Czech Metrology Institute was used to ensure proper traceability and maximum value of calibration.

\section{Minimum detectable activity (MDA)}

The MDA is the minimum radioactive nuclide that can be detected with a degree of certainty (Gilmore, 2008). In low level counting where the sample activity is approximately that of the background, the MDA is necessary. Under this condition the background is counted with the blank which could be the sample holder and everything else that may be counted, except for the analyte (Kenkel, 2003). A 1.0 L Marinneli beaker was filled with deionised water and counted for 36000 s. For ${ }^{226} \mathrm{Ra}$, the MDA was determined using average peak areas of the daughter gamma ray lines $351.92 \mathrm{keV}$ of $214 \mathrm{~Pb}$ and $609.31,1764.5 \mathrm{keV}$ of ${ }^{214} \mathrm{Bi}$. That of $40 \mathrm{~K}$ was determined using the gamma ray line at $1460.83 \mathrm{keV}$. The daughter gamma ray lines of $238.63 \mathrm{keV}$ of ${ }^{212} \mathrm{~Pb}, 583.19 \mathrm{keV}$ and $2614.53 \mathrm{keV}$ of $208 \mathrm{TI}$ and $911.21 \mathrm{keV}$ of ${ }^{228} \mathrm{Ac}$ $\mathrm{keV}$ were used to determine the MDA of ${ }^{232} \mathrm{Th}$

where $\quad M D A=\frac{\sigma \sqrt{ } B}{\mathrm{y} P T V} \ldots \ldots \ldots[1]$

$\boldsymbol{\sigma}$ is the statistical coverage factor equal to 1.645 (confidence level of 95\%),

$\boldsymbol{B}$ is the background for the region of interest of each radionuclide,

$\boldsymbol{T}$ is the counting time in seconds,

$\mathbf{P}$ is the gamma emission probability (gamma yield) of each radionuclide,

$\mathbf{V}$ is the volume of the Marinneli beaker, and

$\boldsymbol{\eta}$ is the photopeak efficiency for the measured gamma ray energy

Calculation of activity concentration

Gamma ray spectral analysis was done using the GENIE 2000 gamma acquisition and analysis software. Activity concentrations for radionuclides of interest $\left({ }^{40} \mathrm{~K},{ }^{232} \mathrm{Th},{ }^{226} \mathrm{Ra}\right)$ were calculated using the equation 


$$
A_{s p}=\frac{N_{D}}{p T_{C} \eta V} e^{\lambda_{p T_{d}}} \ldots \ldots \ldots \ldots[2]
$$

$\mathbf{N}_{\mathbf{D}}$ is the net counts of the radionuclide in the samples,

Td is the delay time between sampling and counting,

$\mathbf{P}$ is the gamma emission probability (gamma yield),

$\boldsymbol{\eta}$ is photopeak efficiency for the measured gamma ray energy,

Tc is the sample counting time (s),

$\mathbf{V}$ is the volume (L) of the beaker, $\mathbf{e}^{\lambda \mathbf{p T d}}$ is the decay correction factor for delay between time of sampling and counting

$\lambda \mathbf{p}$ is the decay constant of the parent radionuclide.

Committed Effective Dose ( $E_{\text {ing }}$ )

Calculation of Committed Effective Doses

The committed effective doses $\left(\mathrm{E}_{\text {ing }}\right)$ were estimated from the activity concentrations of each individual radionuclide and applying the annual water consumption rate for adults of $730 \mathrm{~L} /$ year and the dose conversion factors for ${ }^{232} \mathrm{Th}$, ${ }^{226} \mathrm{Ra}$ and ${ }^{40} \mathrm{~K}$ taken from the safety report 19 and UNSCEAR 2000. Equation 3 was used (IAEA, 2001)

$$
E_{\text {ing }}=A_{s p}(w) \cdot I_{w} \cdot \sum_{j=1}^{3} D C F_{i}(T h, R a, K)
$$

where

$\mathbf{E}_{\text {ing }}(\mathbf{w})$ is the committed doses due to ingestion. $\mathbf{A}_{\mathbf{s p}}(\mathbf{w})$ is the activity concentration of the radionuclides in a sample in $B q / L$, $\mathbf{I}_{\mathbf{w}}$ is the intake of water in litres per year, bb$\mathbf{D C F}_{i}$ is the ingestion dose coefficient in $\mathrm{Sv} / \mathrm{Bq}$

Risk estimation due to ingestion

Ideally, fatal cancer and hereditary risk calculations are functions of the total effective doses. These doses are dependent on all exposure pathways i.e. ingestion, inhalation and immersion. For purposes of this study, only the risk due to ingestion of bottled water was considered and compared to lifetime risk values of $5 x$ $10 \mathrm{~Sv}^{-1}$ (ICRP, 2007) to the public. The risk of exposure to low doses to members of the public who drink bottled water was estimated and assumed 70 years lifetime of continuous exposure of the population to low level radiation.

\section{Results}

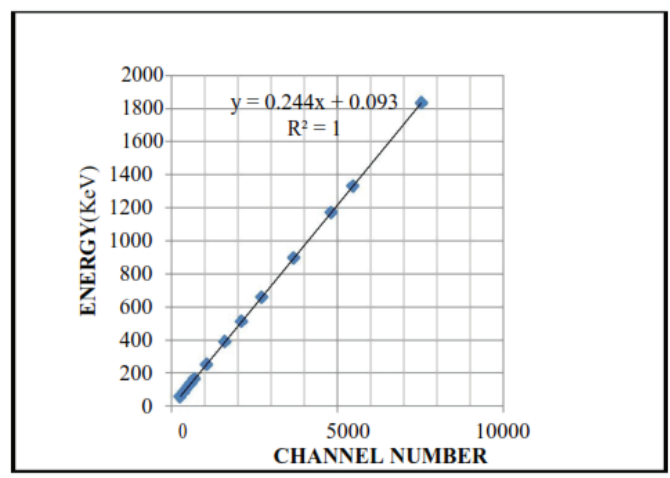

Fig. 2: Energy calibration curve using mixed standard radionuclides (Czech Metrology Institute). 


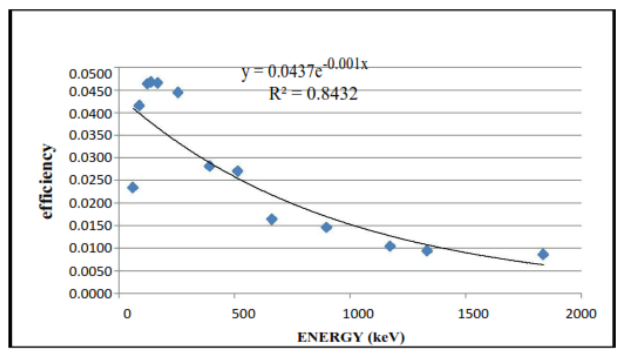

Fig. 3: Efficiency calibration curve as a function of energy for mixed radionuclides.

Fatality cancer risk $=\mathrm{E}_{\text {ing }}(\mathrm{Sv}) \times$ cancer nominal risk factor........ [4]

Hereditary effect $=\operatorname{Eing}(\mathrm{Sv}) \times$ hereditary nominal effect factor........ [5]

TABLE 1

Minimum detectable activity (MDA) of ${ }^{232} \mathrm{Th},{ }^{226} \mathrm{Ra}$ and ${ }^{40} \mathrm{~K}$.

\begin{tabular}{l|c}
\hline NUCLIDE & MDA (Bq/L) \\
\hline${ }^{232} \mathbf{T h}$ & 0.120 \\
${ }^{226} \mathrm{Ra}$ & 0.040 \\
${ }^{40 \mathrm{~K}}$ & 0.150 \\
\hline
\end{tabular}

TABLE 2

Summary of activity concentrations and estimated annual effective doses in the bottled water samples.

\begin{tabular}{|c|c|c|c|c|c|}
\hline \multirow[t]{2}{*}{ I.D } & \multirow[t]{2}{*}{$\mathrm{pH}$} & \multicolumn{3}{|c|}{$\begin{array}{l}\text { ACTIVITY CONCENTRATION } \\
\text { Bq/L }\end{array}$} & \multirow[t]{2}{*}{$\mathrm{E}_{\text {ing }}(\mathrm{mSv} / \mathrm{a})$} \\
\hline & & $40_{K}$ & $232_{\text {Th }}$ & $226_{\mathrm{Ra}}$ & \\
\hline L1 & 6.44 & $3.57 \pm 0.02$ & $0.30 \pm 0.01$ & $0.14 \pm 0.01$ & 0.07 \\
\hline L2 & 6.32 & $5.36 \pm 0.05$ & $0.44 \pm 0.20$ & $0.08 \pm 0.01$ & 0.10 \\
\hline L3 & 6.14 & $4.52 \pm 0.27$ & $0.51 \pm 0.05$ & $0.17 \pm 0.02$ & 0.11 \\
\hline L4 & 5.65 & $4.55 \pm 0.32$ & $0.45 \pm 0.03$ & MDA & 0.10 \\
\hline L5 & 6.40 & $4.70 \pm 0.34$ & $0.47 \pm 0.02$ & MDA & 0.10 \\
\hline L6 & 5.97 & $4.37 \pm 0.28$ & $0.46 \pm 0.03$ & MDA & 0.10 \\
\hline L7 & 6.35 & $5.60 \pm 0.33$ & $0.56 \pm 0.03$ & $0.28 \pm 0.02$ & 0.13 \\
\hline L8 & 5.94 & $4.36 \pm 0.43$ & $0.56 \pm 0.03$ & MDA & 0.11 \\
\hline L9 & 5.40 & $5.74 \pm 0.24$ & $0.42 \pm 0.03$ & $0.53 \pm 0.04$ & 0.11 \\
\hline L10 & 5.02 & $5.05 \pm 0.26$ & $0.37 \pm 0.02$ & $0.18 \pm 0.02$ & 0.09 \\
\hline L11 & 6.00 & $4.73 \pm 0.43$ & $0.37 \pm 0.04$ & $0.14 \pm 0.01$ & 0.09 \\
\hline L12 & 5.50 & $4.67 \pm 0.24$ & $0.45 \pm 0.02$ & $0.16 \pm 0.01$ & 0.10 \\
\hline L13 & 5.64 & $5.01 \pm 0.34$ & $0.32 \pm 0.02$ & $0.17 \pm 0.02$ & 0.08 \\
\hline L14 & 5.80 & $5.41 \pm 0.41$ & $0.36 \pm 0.03$ & MDA & 0.08 \\
\hline L15 & 6.22 & $5.30 \pm 0.31$ & $0.32 \pm 0.02$ & $0.18 \pm 0.01$ & 0.08 \\
\hline L16 & 6.12 & $4.98 \pm 0.35$ & $0.45 \pm 0.03$ & $0.19 \pm 0.02$ & 0.11 \\
\hline Range & $5.02-6.44$ & $3.57-5.74$ & $0.30-0.56$ & $0.00-0.53$ & $0.07-0.13$ \\
\hline Mean & 5.93 & 4.87 & 0.43 & 0.14 & 0.10 \\
\hline SD & 0.40 & 0.55 & 0.08 & 0.14 & 0.01 \\
\hline
\end{tabular}

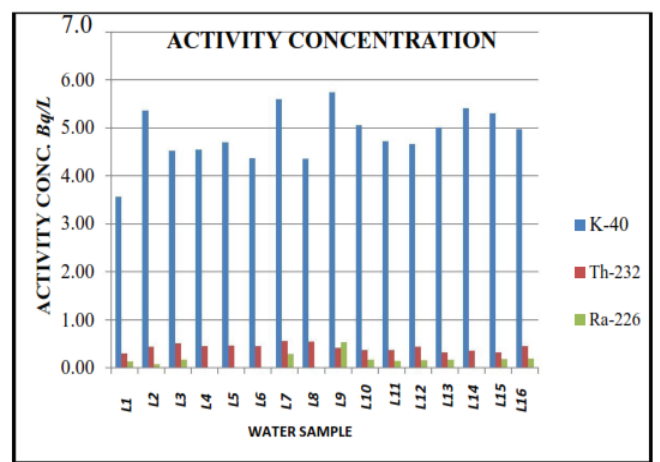

Fig. 4: Activity concentrations of ${ }^{232} \mathrm{Th},{ }^{226} \mathrm{Ra} \&{ }^{40} \mathrm{~K}$ in water samples.

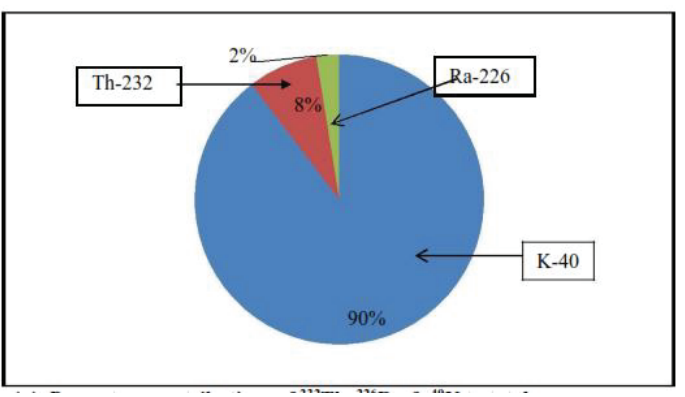

Fig. 5: Percentage contributions of ${ }^{232} \mathrm{Th},{ }^{226} \mathrm{Ra} \&{ }^{40} \mathrm{~K}$ to total gamma activity.

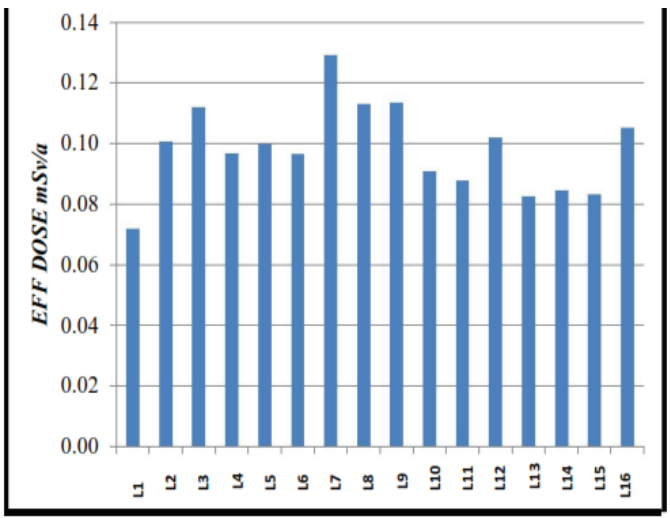

Fig. 6: Estimated annual effective doses due to continuous ingestion of water. 
TABLE 3

Fatality cancer and hereditary risk to adults.

\begin{tabular}{cccc}
\hline I.D & $\begin{array}{c}\text { Fatality cancer } \\
\text { risk } \times 10^{-7}\end{array}$ & $\begin{array}{c}\text { Hereditary } \\
\text { risk } \\
\times 10^{-8}\end{array}$ & $\begin{array}{c}\text { Total } \\
\text { detriment } \\
\times 10^{-7}\end{array}$ \\
\hline L1 & 4.04 & 0.98 & 4.13 \\
L2 & 5.65 & 1.38 & 5.79 \\
L3 & 6.30 & 1.54 & 6.45 \\
L4 & 5.43 & 1.32 & 5.56 \\
L5 & 5.60 & 1.37 & 5.74 \\
L6 & 5.43 & 1.32 & 5.56 \\
L7 & 7.25 & 1.77 & 7.43 \\
L8 & 6.35 & 1.55 & 6.51 \\
L9 & 6.38 & 1.56 & 6.54 \\
L10 & 5.11 & 1.25 & 5.23 \\
L11 & 4.93 & 1.20 & 5.05 \\
L12 & 5.73 & 1.40 & 5.87 \\
L13 & 4.63 & 1.13 & 4.75 \\
L14 & 4.75 & 1.16 & 4.87 \\
L15 & 4.68 & 1.14 & 4.79 \\
L16 & 5.91 & 1.44 & 6.05 \\
\hline
\end{tabular}

\section{Discussion}

Bottled water brands were obtained randomly and directly from the shelves so as to directly "mimic" the exact mode by which the brands were obtained. This would imply the estimated committed doses would represent consumer doses due to BW intake. The brand identities were removed and relabeled (Table A1). The brands were already sealed with safety caps as well as additional polythene seals. Acidification (using $\mathrm{HNO}_{3}$ ) before transportation as in the practice for freshwater samples was not done. This is because radionuclides that may stick to the container walls need not be reintroduced into the water since the consumer would not ingest it either.

\section{Activity concentrations}

In general, nuclides identified were ${ }^{226} \mathrm{Ra}(\gamma$-ray lines of $351.92 \mathrm{keV}$ of ${ }^{214} \mathrm{~Pb}$ and $609.31,1764.5$
$\mathrm{keV}$ of $\left.{ }^{214} \mathrm{Bi}\right),{ }^{232} \mathrm{Th}(\gamma$-ray lines of $238.63 \mathrm{keV}$ of ${ }^{212} \mathrm{~Pb}, 583.19 \mathrm{keV}$ and $2614.53 \mathrm{keV}$ of ${ }^{208} \mathrm{TI}$ and $911.21 \mathrm{keV}$ of $228 \mathrm{Ac}$ ) and ${ }^{40} \mathrm{~K}$ ( $\gamma$-ray lines of $1460.83 \mathrm{keV})$. Higher activity concentrations were estimated for ${ }^{40} \mathrm{~K}$ in the range of 3.57 $\mathrm{Bq} / \mathrm{L}$ to $5.74 \mathrm{~Bq} / \mathrm{L}$ (Table 2). This was expected since $40 \mathrm{~K}$ is abundant in natural systems and could also be as a consequence of potassium ion-exchange resins used by some treatment facilities. Sample L9 showed highest potassium levels followed by L7, L2 and L14 (Fig. 4). Though specific guidance values are not given for this nuclide due to the normally low risk levels associated, critical groups like children $(<1)$ and patients suffering from renal failure, hypertension, diabetes etc. may be susceptible to its presence.

Thorium-232 levels were about three times higher than $226 \mathrm{Ra}$ with a mean reported value of $0.43 \mathrm{~Bq} / \mathrm{L}$ ranging from $0.30 \mathrm{~Bq} / \mathrm{L}$ to $0.56 \mathrm{~Bq} / \mathrm{L}$. This was expected due to the fact that the most of the samples were slightly acidic and ${ }^{232} \mathrm{Th}$ is soluble in groundwater than in surface waters (Durance, 1986). It was highest in samples L7 and L8 with L3 following. ${ }^{232} \mathrm{Th}$ levels were below recommended guidance levels of $1 \mathrm{~Bq} / \mathrm{L}$ (WHO, 2011). Though radiotoxicity categorization had not been established for ${ }^{232} \mathrm{Th}$, its long-term health effects cannot be underestimated. The major concern to low exposure is the risk of lung and pancreatic cancer (US-EPA, 2015).

${ }^{226} \mathrm{Ra}$ levels were the lowest with a mean of $0.14 \mathrm{~Bq} / \mathrm{L}$ and maximum of $0.53 \mathrm{~Bq} / \mathrm{L}$. Some showed no activity in the energy ranges of the reference daughter radionuclides and therefore classified as below detection limit (MDA). $226 \mathrm{Ra}$ emits alpha particles with associated gamma rays. As long as it remains outside the human body, $226 \mathrm{Ra}$ poses little hazard. If, 
however ingested, its radioactivity may lead to an elevated risk of lung and bone cancer. It is chemically toxic at high concentrations and may affect critical organs like the kidney and lungs. The provisional guideline in drinking water is $1 \mathrm{~Bq} / \mathrm{L}$ (WHO, 2011). The measured values were far below this level.

Summarily activity concentrations were in the order ${ }^{40} \mathrm{~K}>{ }^{232} \mathrm{Th}>{ }^{226} \mathrm{Ra}$. An analysis of variance (ANOVA) conducted on the data showed far higher calculated F-value to the critical F-value (Fcal $>>>$ Fcrit) at the 0.05 significance level. This implies at least one of the data set is significantly different from the others. An attempt was made to establish if the difference is due to systemic variances ( $\sigma 2$ sys) or random ones ( $\sigma 2$ rand). The result proved that variance due to systemic difference between the samples is an order of magnitude greater than the variance due to the methods precision ( $\sigma 2$ sys $\gg>\sigma 2$ rand). This means the results are due to the inherent properties of the samples and not attributable to the $\gamma$-spectroscopy method. Again, an attempt was made in determining which of the sample means resulted in the significant differences. A Fisher Least Square Differences (LSD) approach was used at $95 \%$ confidence interval. Significant systemic differences occurred between the means (texp $>t 0.05,45)$ of the respective activity concentrations of ${ }^{40} \mathrm{~K},{ }^{232} \mathrm{Th}$ and ${ }^{226} \mathrm{Ra}$.

\section{Committed dose}

The AD was estimated from the activity concentrations of the identified radionuclides taking into consideration, the annual water consumption rate (IAEA, 1996.) and the appropriate ingestion dose conversion coefficients (ICRP, 2012). Various age groups were also considered as the critical group exist in this domain. The recommended effective dose is $0.1 \mathrm{mSv} / \mathrm{y}$ (WHO, 2011). Generally, there were low AD estimated from ages one and above. For the adult group $(>17 \mathrm{yr})$, the maximum estimate was $0.1292 \mathrm{mSv} / \mathrm{y}$ corresponding to sample L7 (Table 4). AD estimates for this group were slightly closer to the guidance value which is expected mainly due to their high average water consumption rate. The preceding age group (12-17) also had relatively higher AD though below the recommended value. The mean for this group was $0.0879 \mathrm{mSv} / \mathrm{y}$ with an associated 0.0135 standard deviation. Ages one to 12 however, showed very low annual doses, about 1.75 times lower than the recommended values. An issue of concern was found in the infants $(<1 \mathrm{yr})$; where estimates were higher than recommended values with the lowest being $0.2948 \mathrm{mSv} / \mathrm{y}$ and the highest of $0.5439 \mathrm{mS} / \mathrm{y}$, the mean estimate here was $0.4073 \mathrm{mSv} / \mathrm{y}$. Though this is high, it is important to note that about $95 \%$ is due to gamma activity from $40 \mathrm{~K}$. A baby at this stage is supposed to be on exclusive breastfeeding for which reason it is not expected to be introduced to such activity 'loads'.

However, knowing the recent trend where busy mothers prefer to prepare infant formula with bottled water may not be appropriate

\section{Risk assessment}

The ICRP risk assessment methodology (ICRP, 2007) was used in evaluating the fatality cancer and hereditary risk (Table 3 ). The ICRP predicts that, with the availability of new data on dose-response due to low dose range, that below and around $100 \mathrm{mSv}$, it is scientifically reasonable to assume that the incidence of cancer or hereditary effects will rise in direct proportion to an increase in the equivalent dose in the relevant organs or tissues (ICRP, 2007). The evaluation of risk covered only the exposure pathway considered in this study-ingestion. 


\section{Conclusion}

16 brands of bottled drinking water were analyzed for natural radioactivity using gamma spectrometry. Activity concentrations of the NORMs analyzed were generally low which resulted in low effective doses below recommended levels. ${ }^{40} \mathrm{~K}$ activity concentrations were in the range of 3.57-5.47 Bq/L, the highest occurring in sample L9. Similarly, ${ }^{232} \mathrm{Th}$ activity concentrations were in the range of $0.30-0.56$ $\mathrm{Bq} / \mathrm{L}$ with the highest occurring in sample L8.

${ }^{226} \mathrm{Ra}$ was identified in eleven brands with the remaining below detection limit. The highest value $(0.53 \mathrm{~Bq} / \mathrm{L})$ occurred in sample L9. Comparison of the mean concentrations showed significant differences at $\alpha=0.05$. The identified radionuclides contributed to systemic statistical differences. None of the radionuclides exceeded the maximum allowable averages for drinking water worldwide.

Consequently, the potential exposure was evaluated by estimating the annual effective doses due to ingestion of BW by the population. The estimated committed effective doses were generally below $0.1 \mathrm{mSv} / \mathrm{a}$ for all age groups with the exception of children $<1 \mathrm{yr}$. This should be situated in the context of the radionuclide's toxicity. However, protecting infants from associated health risks of exposure provides justification for additional costs that might be incurred in the re-examination of the water treatment procedures in the country.

The range of fatality cancer risk is 4.04-7.25(x10$\left.{ }^{7}\right)$.. This means at a minimum four persons out of 10 million people would suffer fatal cancer on continuous ingestion of BW. The range of hereditary effect is $0.98-1.77\left(\mathrm{x} 10^{-8}\right)$. A similar low risk analogy can be drawn to which the hereditary effects are extremely low. The total detriment is combination of both the fatality cancer risk and the hereditary risk hence the total detriment can be said to be very low. Estimated lifetime cancer and hereditary risk was done using the ICRP risk assessment methodology (2007). The negligible cancer fatality risk value recommened by USEPA is in the range of $1 \times 10^{-6}$ to $1 \times 10^{-4}$, however the estimated fatality cancer risk was far below the recommended minimum. Therefore, bottled water on the Ghanaian market is radiologically safe and there is no need for special radiological assessment.

Appendix A

TABLE A1

Brands assigned I.D.

\begin{tabular}{lll}
\hline BRAND & I.D & CATEGORY \\
\hline Voltic & L1 & NMW \\
Bel-aqua & L2 & PW \\
Aqua fill & L3 & NMW \\
Valley fresh & L4 & NMW \\
Nero & L5 & NMW \\
Bueno & L6 & NMW \\
Verna & L7 & NMW \\
Everpure & L8 & PW \\
Special ice & L9 & NMW \\
Vaettel & L10 & NMW \\
Icepak & L11 & PW \\
ESE & L12 & NMW \\
Aquasplash & L13 & PW \\
Ecospa & L14 & NMW \\
Bonaqua & L15 & PW \\
Ice cool & L16 & PW \\
\hline
\end{tabular}

NB arranged in no special order 


\section{References}

Agyekum, W. (2002) Groundwater resources of Ghana with focus on the International Shared Aquifer Boundaries. CSIR-WRI. Proceedings of the international workshop in Tripoli, Libya, 2nd 4th June.

Awudu, A. R., Glover, E. T. \& Kpordzro, R. (2011) Determination of radionuclides in underground water sources within the environments of University of Cape Coast. J. Env. and Earth Sci. 6, 269 - 274.

Back, W., Landa, E. R. \& Meeks, L. (1995) Bottled water, spas \& early years of Water Chemistry. Groundwater 33 (4), 606 - 614.

Cember \& Johnson (2009) Introduction to Health Physics. McGraw -Hill, 4th edition.

Choppin, G., Liljenzin, J. \& Rydberg, J. (2002) Radiochemistry and Nuclear Chemistry. Butterworth-Heinemann, 3rd Ed.

Codex Alimentarius Commission (2008) Codex standard for natural mineral waters. CODEX STAN 108-1981. Rome, Italy.

Dapaah-Siakwan,S. \& Gyan-Boakye, P. (2000) Hydrogeological framework and borehole yields in Ghana. Hydrogeological Journal 6 (4), 405 $-416$.

DARKo, E. O \& FAANU, A. (2007) Baseline radioactivity measurements in the vicinity of a Gold Treatment Plant, J. App. Sci. and Tech. 12 (1 \& 2), $18-24$.

Harvey, D. (2000) Modern Analytical Chemistry 1st ed. McGraw Hill Company Inc.

Doria, M. F., (2006) Bottled water versus Tapwater: Understanding Consumers "Preferences. Journal of Water and Health 4 (2).

Dozol, M. \& Hagemann, R. (1993) Radionuclide Migration in Groundwater: Review of the behavior of Actinides. J. Pure Appl. Chem. 65, 1081.
Dragani, G, Draganic Z. D. \& Adloff J. P. (1990) Radiation and Radioactivity on the Earth Surface and Beyond. CRC Press, Boca Raton, Florida. USA.

Dueñas, C., Fernández, M. C., Lieger, E. \& CarretERO, J. (1997) Natural Radioactivity levels in bottled water in Spain. J. Water Res. 31 (8), 1919 - 1924.

Durance, E. M. (1986) Radioactivity in Geology. Principles and Applications. Ellis Horwood, Chichester.

Norman, E. B. (1994) Stellar Alchemy: The origin of the Chemical Elements. J. Chem.educ. 71, 813.

FaAnu, A., Darko, E. O. \& Ephraim J. H. (2011) Determination of Natural Radioactivity in soil and rock samples in a mining area in Ghana. J. Appl. Ecology, 19, 77 - 90.

FAO (2015) Irrigation in Africa in figures, AQUASTAT survey. Rome, Italy.

Gbadago, J. K., Faanhof, A. \& Schandorf, C. (2011) Contribution of Natural Radionuclides in a domestic water of two critical gold mining communities in Ghana. J. Water Qual. Expo. Health. 3, 149.

Gilmore, G. R. (2008) Practical Gamma Ray Spectrometry. 2nd ed. John Wiley \& Sons Ltd.

Gyan-Boakye, P. \& DapaAh-Siakwan, S. (2000) Groundwater as a source of rural water supply in Ghana. J. Appl. Sci. and Tech. 5 (1\&2), 77 -86 .

IAEA (1989) Measurement of Radionuclides in Food and Environment. A Guidebook, IAEA-Technical Reports Series No. 295, Austria.

IAEA (1996) Regulations for the Safe Transport of Radioactive Material, 1996 Edition (Revised). IAEA Safety Standards Series No. TS-R-1 (ST1, Rev.), IAEA, Vienna (2000). 
IAEA (2001) Generic models for use in assessing the impact of discharges of radioactive substances to the environment. Safety report series 19 , Vienna, Austria.

ICRP (2007) The 2007 Recommendations of the International Commission on Radiological Protection. ICRP Publication 103. Ann. ICRP $37(2-4)$.

ICRP (2012) Compendium of dose coefficients based on ICRP publication 60. 1CRP publication 119. Ann. ICRP 41 (suppl.).

Jobbágy, V., Dirican, A. \& Wätjen U. (2013) Radiochemical Characterization of mineral water for a European interlaboratory comparison. Microchemical Journal 110, 675 - 680.

JunNer, N. R. \& Hirst T. (1946) The geology and hydrology of the Volta basin. Gold Coast Geological Survey (Memoir 8).

Karamanis, D., Stamoulis K. \& Ioannides K. G., (2007) Natural Radionuclides and Heavy metals in bottled water in Greece. J. Water Desalination 213, 90 - 97.

Kenkel, J. (2003) Analytical Chemistry for Technicians, 3rd ed. CRC Press LLC. Boca Raton, Florida.

Kortatsi, B. K. (1994) Groundwater Utilization in Ghana. Proceedings of International Conference. Helsinki, Finland.

Lieser, K. H., Ament, A., Hill, R., Singh, R. N., Stingl, U. \& Thybusch, B. (1990) Colloids in Groundwater and their influence on migration of trace elements and Radionuclides. Radiochim, hota. 49, 83 .

Lieser, K. H. (2001) Nuclear \& Radiochemistry Fundamentals and Applications. Wiley-VCH, 2nd ed. Germany.

Loveland, W. D., Morrisey, D. J. \& Seaborg, G. T. (2006) Modern Nuclear Chemistry. Wiley \& Son Inc, New Jersey.
Maddock, A. G. \& Willis, E. H. (1961) Atmospheric Activities and Dating Procedures. Adv. Inorg. radiochem 2, 287.

Manahan, S. E. (2000) Env. Chemistry. 7th ed. Boca Raton. CRC Press LLC.

Oyelude, E. O. \& Ahenkorah, S. (2012) Quality of Sachet Water and Bottled Water in Bolgatanga Municipality of Ghana. Journal of Applied Sciences, Engineering and Technology 4 (9), 1094 - 1098.

Patnaik, P. (2004) Deans Analytical Chemistry Handbook. 2nd ed. McGraw Hill Inc.

TISDA (2011) Ghanae's national water supply integrity studies, Ghana Integrity Initiative. Accra, Ghana.

Unesco (2008) Ghana National Commission for UNESCO, Water for Life Report, Accra, Ghana.

United Nations (2010) Unscear 2008 Report.Source and Effects of Ionizing Radiation, vol. 1. New York.

United Nations (2013) The Millennium Development Goals Report 2013, New York.

USEPA (2006) Edition of the Drinking Water Standards and Health Advisories, EPA 822-R-06013, Washington DC.

WARNER, G. \& JABBAR, T. (2010) Natural radionuclides in Austrian bottled mineral waters. J. Radioanal. Nucl. Chem.., 286, 329 - 324.

World Water Assessment Programme (2009) The United Nations World Water Development Report 3: Water in a Changing World. Paris: UNESCO, and London: Earthscan.

WHO (2011) Guidelines for drinking- water quality, 4th ed. Geneva, Switzerland.

Received 3 May 18; revised 3 Nov 18. 